\title{
Modelling Technique for the Assessment of the Sub-Soil Drain for Groundwater Seepage Remediation
}

\author{
Mohamad Faizal Tajul Baharuddin ${ }^{1,2,}$, Saiful Azhar Ahmad Tajuddin ${ }^{1}$, Mohd Hazreek \\ Zainal Abidin ${ }^{1}$, and Aziman Madun ${ }^{1}$ \\ ${ }^{1}$ Research Center for Soft Soils, Faculty of Civil and Environmental Engineering, Universiti Tun \\ Hussein Onn Malaysia, 86400 Batu Pahat, Johor, Malaysia. \\ ${ }^{2}$ Dept. of Water and Environmental Engineering, Faculty of Civil and Environmental Engineering, \\ Universiti Tun Hussein Onn Malaysia, 86400 Batu Pahat, Johor, Malaysia
}

\begin{abstract}
Groundwater simulation technique was carried out for examining the performance of sub-soil drain at problematic site area. Subsoil drain was proposed as one of solution for groundwater seepage occurred at the slope face by reducing groundwater table at Taman Botani Park Kuala Lumpur. The simulation technique used Modular ThreeDimensional Finite Difference Groundwater Flow (MODFLOW) software. In transient conditions, the results of simulation showed that heads increases surpass 1 to $2 \mathrm{~m}$ from the elevation level of the slope area that caused groundwater seepage on slope face. This study attempt to decrease the heads increase surpass by using different sub-soil drain size in simulation technique. The sub-soil drain capable to decline the heads ranges of 1 to $2 \mathrm{~m}$.
\end{abstract}

\section{Introduction}

Groundwater seepage occurs on slope face may induced slope failures in the future if any relevant action is not taken. This seepage is triggered by existence of high pore water pressure in soil profiles. High pore water pressure measurements always related to groundwater tables observed at site and required a huge number of piezometers installation [1-2]. These works are involved intensive time and cost, and incomplete data coverage. The numerical groundwater flow model simulation technique will be able to overcome the limitation of the above method [3-5].This study used groundwater simulation technique for examining groundwater seepage appears at problematic slope face in Botani Park Kuala Lumpur. In addition, sub-soil drain approach was used in attempt to solve groundwater seepage by carried out groundwater modelling technique.

\footnotetext{
*Corresponding author: mdfaizal@uthm.edu.my
} 


\section{Materials and Method}

Panggung Anniversary of Botani Park in Kuala Lumpur was chosen as the study area to assess the ability of groundwater flow simulation technique in identifying the cause of seepage groundwater occurrence (Fig. 1 and 2). The establishment of conceptual model in groundwater simulation technique is important to set-up groundwater flow systems in study area. The model normally presented in the form of a block diagram or a cross section [6]. A few assumptions were made on conceptual model especially on the aquitard (sandy silt) layers and hydraulic properties. The model only considers the north and south of Panggung Anniversary as boundary condition with applied constant head boundary (Fig. 3). The observed water levels in the study were used to adjust the hydrogeology parameters applied in this model. Medium to coarse grained sand with dominant silt material formed the aquitard soil layer [7]. Aquitard thickness ranging from 13 to $25 \mathrm{~m}$ presumed as unconfined layer. The bedrock encountered at depths ranging from 13.0 to $25.0 \mathrm{~m}$ consists of interbedded shale and sandstone. Hydraulic conductivity ranging from $1.48 \times 10^{-7}$ to $3.50 \times 10^{-8}$ $\mathrm{cm} / \mathrm{sec}$ with an average of $9.25 \times 10^{-8} \mathrm{~cm} / \mathrm{sec}$ was used in the study for this area.

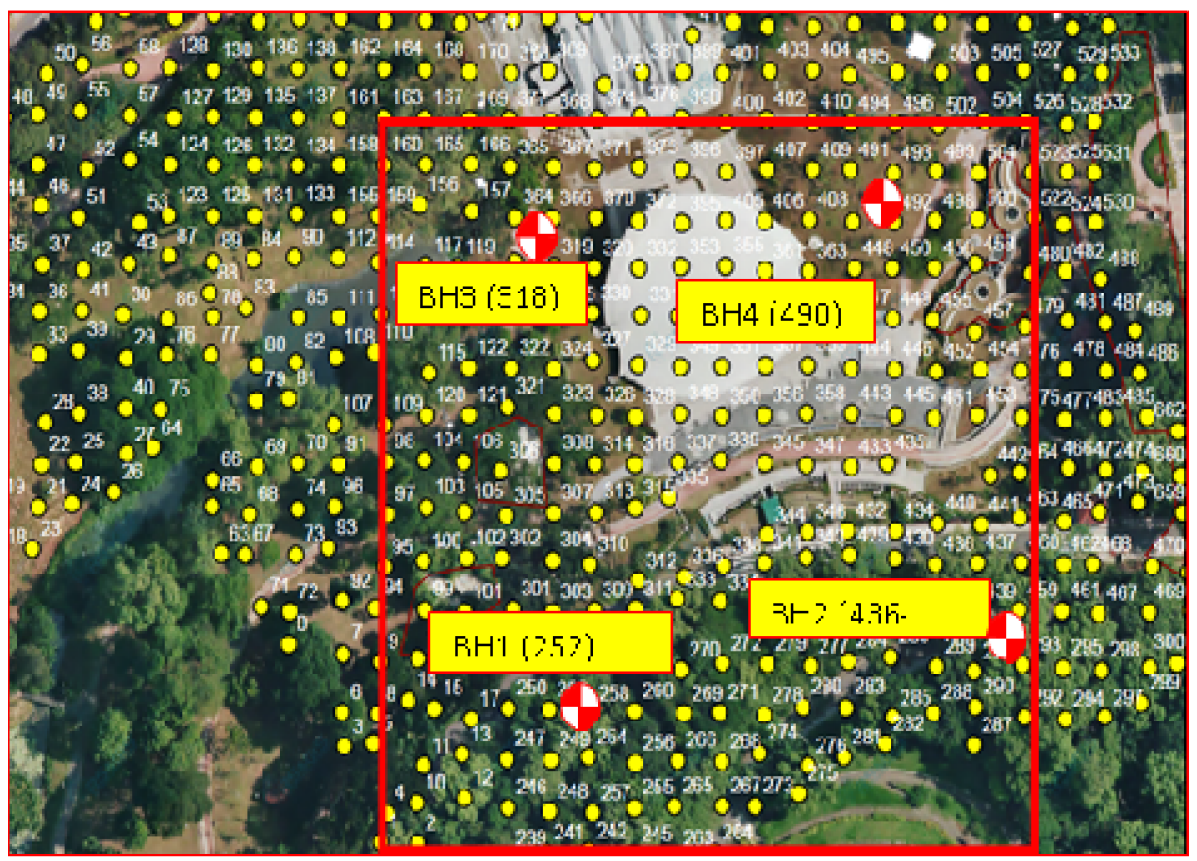

Fig. 1.The boundary locations of study area, boreholes location and surface elevation 


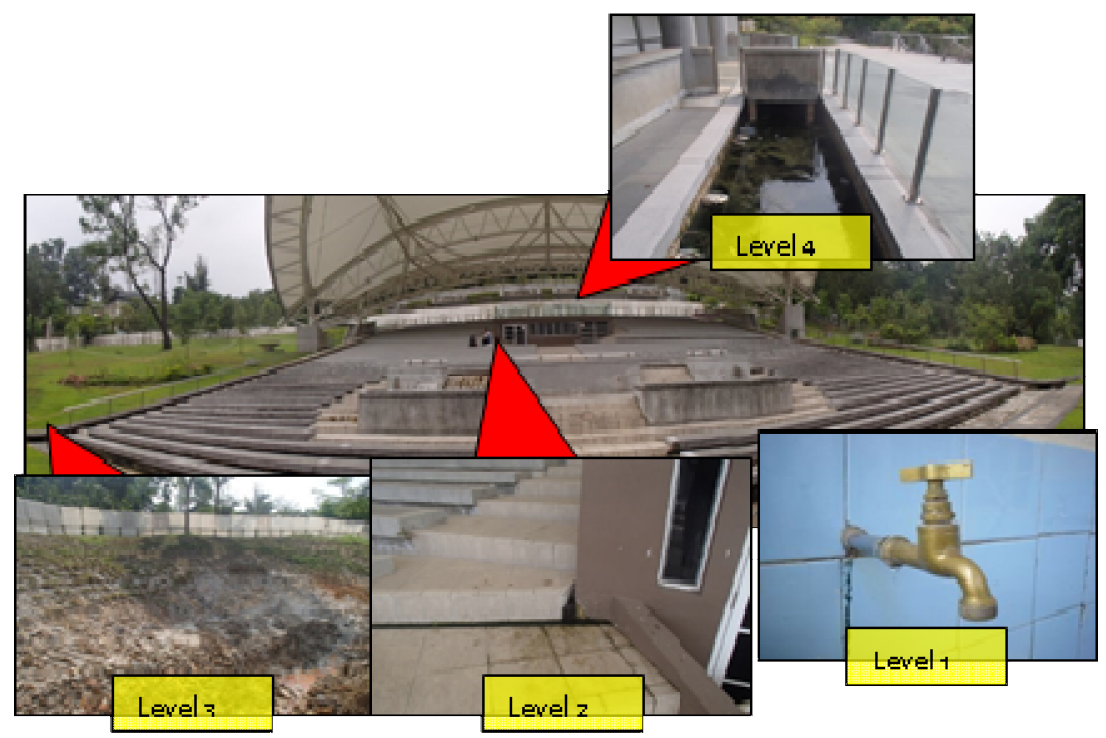

Fig. 2. Groundwater seepage locations at site

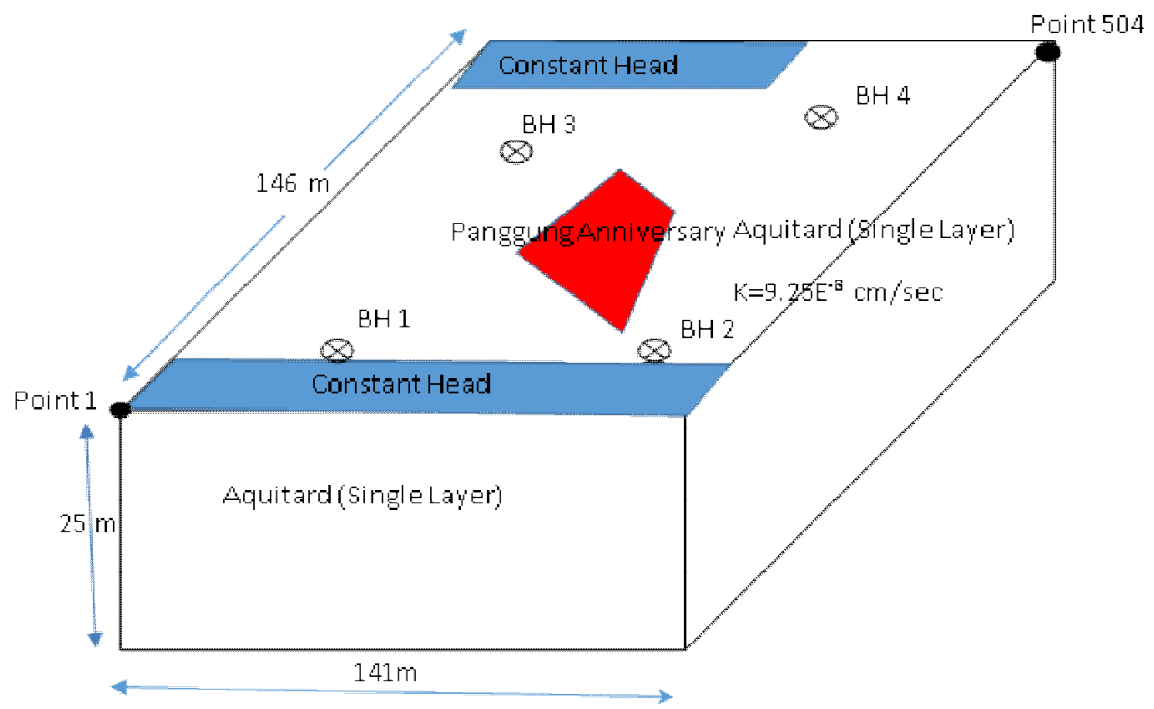

Fig. 3.Numerical and conceptual model at site.

\subsection{Numerical model setup}

Visual MODFLOW was used in creating three-dimensional representation of the site. In able to accelerate and facilitate the development of the MODFLOW model, Visual MODFLOW (Version 2003.3.1.0.85) was used to compile the input files. The threedimensional model was constructed as a $141 \mathrm{~m} \mathrm{x} 146 \mathrm{~m}$ area in the $\mathrm{x}$ and y directions (eastwest and north-south directions, respectively) (Fig. 4). Total station theodolite was used to obtain the topography data from field survey (Fig. 1). The topography model (the first layer) was extracted from the elevation data for the wells (BH1-BH4). Surface elevations of the site was constructed by the digital elevation model. A total station theodolite was 
utilized to determine the relative elevations of water level monitoring points. The hydraulic heads in the model used mean sea level as the reference point (rectified skew orthomorphic). This permitted the assignment of the piezometer screens in the model at the terminated borehole depth.

\subsection{Model parameters}

The analysis data of permeability tests from $\mathrm{BH} 2$ and $\mathrm{BH} 3$ was used in estimating the hydraulic conductivities of the model layer. The dynamic viscosity value was used for estimating hydraulic condivities is about $8.01^{-4} \mathrm{~Pa} \cdot \mathrm{s}$ at $30^{\circ} \mathrm{C}$. As the data were not enough to determine heterogeneity layer in this area, a single layer model was presumed to have uniform hydraulic properties. The data from previous studies [8-11] (Table 1) was utilized to estimate the model parameters data such as specific yields (Sy), specific storage (Ss), total porosity and effective porosity. Annual precipitation value of $5 \%$ and $20 \%$ of was used as an estimate of recharge for unavailable data [8]. The model calibration and validation processes has been carried out and recharge was found to be $10 \%$ of the average annual precipitation. $10 \%$ of total annual rainfall at open area was estimated as the recharge parameter of surface water into groundwater system [8]. Recharge parameter with zero value was used in closed area because there is no infiltration or recharge occur due to the concrete coverage of the Panggung Anniversary stage. Evapotranspiration values was estimated using 1.44 times by total annual transpiration at open area and zero value of evapotranspiration was imposed in closed area [8].

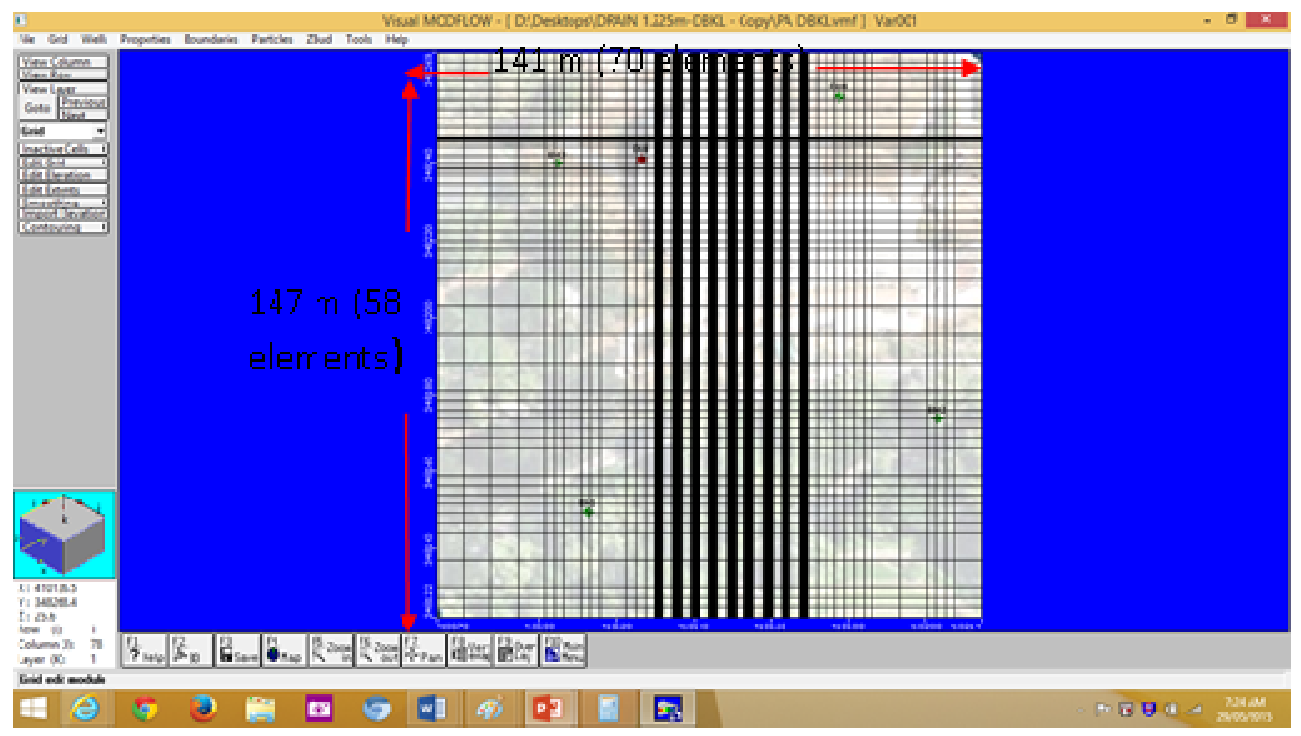

Fig. 4. Dimension of the grid mesh refine and area

\subsection{Boundary Conditions}

Northern and southern edges of the modelled area which are bounded by groundwater head of BH1-BH2 (south) and BH3-BH4 (north) were assigned with constant head boundaries. The heads in the model was referred at mean sea level datum. This depth was on average 5 $\mathrm{m}$ below the ground surface. The highest heads with an average head level of $48 \mathrm{~m}$ was located at the south area meanwhile the lowest heads with an average $38 \mathrm{~m}$ was located at 
the south area. DRAIN Package was applied as the model setup for the remediation technique in Visual MODFLOW software.

Table 1. Input for model parameters

\begin{tabular}{|l|l|}
\hline \multicolumn{1}{|c|}{ Parameters } & \multicolumn{1}{c|}{ Value } \\
\hline $\mathrm{K}_{\mathrm{x}}(\mathrm{cm} / \mathrm{sec})$ & $\begin{array}{l}9.25 \mathrm{e}-8(\text { average value from hydraulic conductivity test at } \mathrm{BH} 2 \\
\text { and BH3) }\end{array}$ \\
\hline $\mathrm{K}_{\mathrm{y}}(\mathrm{cm} / \mathrm{sec})$ & $\begin{array}{l}9.25 \mathrm{e}-8(\text { average value from hydraulic conductivity test at } \mathrm{BH} 2 \\
\text { and BH3) }\end{array}$ \\
\hline $\mathrm{K}_{\mathrm{z}}(\mathrm{cm} / \mathrm{sec})$ & $1 \mathrm{e}-9[9]$ \\
\hline $\mathrm{S}_{\mathrm{s}}$ & $1 \mathrm{e}-5[10]$ \\
\hline $\mathrm{S}_{\mathrm{y}}$ & $0.8[11]$ \\
\hline Total Porosity & $0.3[11]$ \\
\hline $\begin{array}{l}\text { Effective Porosity } \\
0.15[11]\end{array}$ \\
\hline Recharge (mm/year) & $\begin{array}{l}220(10 \% \text { of Annual Rainfall at barren area and } 0 \text { at Panggung } \\
\text { Anniversary [8] }\end{array}$ \\
\hline $\begin{array}{l}\text { Evapotranspiration } \\
\text { (mm/year) }\end{array}$ & 500 and 0 at Panggung Anniversary [8] \\
\hline Conductance (m /day) & $0.00094-0.00562$ \\
\hline
\end{tabular}

\subsection{Transient groundwater flow simulation and calibration}

A partial differential equation was used as the equation for groundwater flow through the porous media:

$$
\frac{\partial}{\partial x}\left(K_{x} \frac{\partial h}{\partial x}\right)+\frac{\partial}{\partial y}\left(K_{y} \frac{\partial h}{\partial y}\right)+\frac{\partial}{\partial z}\left(K_{z} \frac{\partial h}{\partial z}\right)=S_{S} \frac{\partial h}{\partial t}-W
$$

where $\mathrm{K}_{\mathrm{x}}, \mathrm{K}_{\mathrm{y}}$, and $\mathrm{K}_{\mathrm{z}}$ are the hydraulic conductivities in the three orthogonal directions $(\mathrm{m} / \mathrm{s}$ or $\mathrm{ft} /$ day), $\mathrm{h}$ is the head that drives the flow or the saturated thickness of the aquifer ( $\mathrm{m}$ or $\mathrm{ft}$ ), $\mathrm{W}$ is the volumetric flux per unit volume and represents the source/sink term for water or withdrawal $\left(\mathrm{m}^{3} / \mathrm{s}\right.$ or $\mathrm{ft}^{3} /$ day), Ss is the specific storage capacity of the porous medium (dimensionless), and $\mathrm{t}$ is the time ( $\mathrm{s}$ or day). When the water withdraws, $-\mathrm{W}=\mathrm{R}$, where $\mathrm{R}$ is a general sink/source term, it is defined to be intrinsically positive to represent recharge (defines the volume of inflow to the system per unit volume of aquifer per unit of time $\left(\mathrm{ft}^{3} / \mathrm{ft}^{3} /\right.$ day or $\left.\mathrm{m}^{3} / \mathrm{m}^{3} / \mathrm{s}\right)$ ). The Visual MODFLOW model was run in transient state subsequently then calibrated to hydraulic heads recorded on a weekly basis from 16 April 2015 to 7 May 2015 at four standpipes (BH1-BH4) for calibration. An analysis of the observed versus computed water levels for each transient model run was conducted to determine the accuracy of the simulation. 


\section{Result and discussion}

\subsection{Calibration Groundwater Model}

The computed difference between the simulated and the observed hydraulic heads was obtained from the assessment of the model fit. In this model the indication of a well calibrated model was shown by the estimated average of mean absolute error (MAE) of 0.5 $\mathrm{m}$, the root mean square (RMS) of $1.2 \mathrm{~m}$, and $12 \%$ of the normalized root mean square error (NRMS). As a result, the calibrated model was able to be use to simulate water levels and water level fluctuations satisfactorily to appraise the options of remediation methodology for groundwater seepage problem.

\subsection{Sub-Soil Drain}

In order to overcome a groundwater seepage problem at levels 2 and 4, remediation method using sub-soil drain was proposed. Two options on the sub-soil drain dimensional design were recommended taking into consideration of the availability of the materials in market.

Option 1:- $0.15 \mathrm{~m}$ (diameter), $40 \mathrm{~m}$ (length), $0.60 \mathrm{~m}$ (depth)

Option 2:- $0.10 \mathrm{~m}$ (diameter), $40 \mathrm{~m}$ (length), $0.60 \mathrm{~m}$ (depth)

Option 1 and 2 sub-soil drain showed heads result in ranges between 41 and $44 \mathrm{~m}$ at level 2 and 4 (Fig. 5 and 6), respectively. Drawdown is the difference in the head between the initial head (without sub-drain) and the head with sub-drain (option 1) showed difference of 1-2 $\mathrm{m}$. It was suggested that option 1 and 2 to be use in the remediation of the groundwater seepage. This solution can reduced the heads to the optimal values to inhibit settlement of the stage structure.

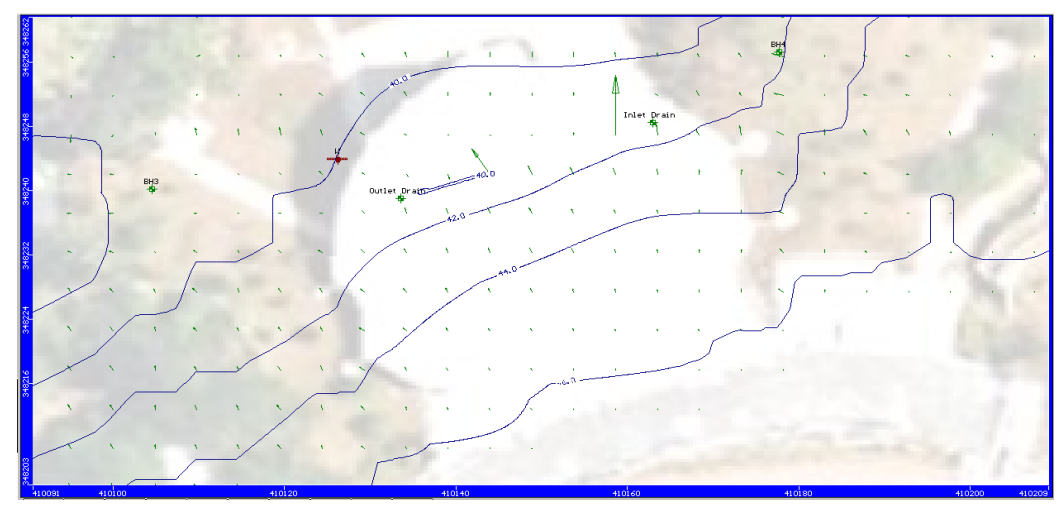

Fig. 5. Head results for Option 1 


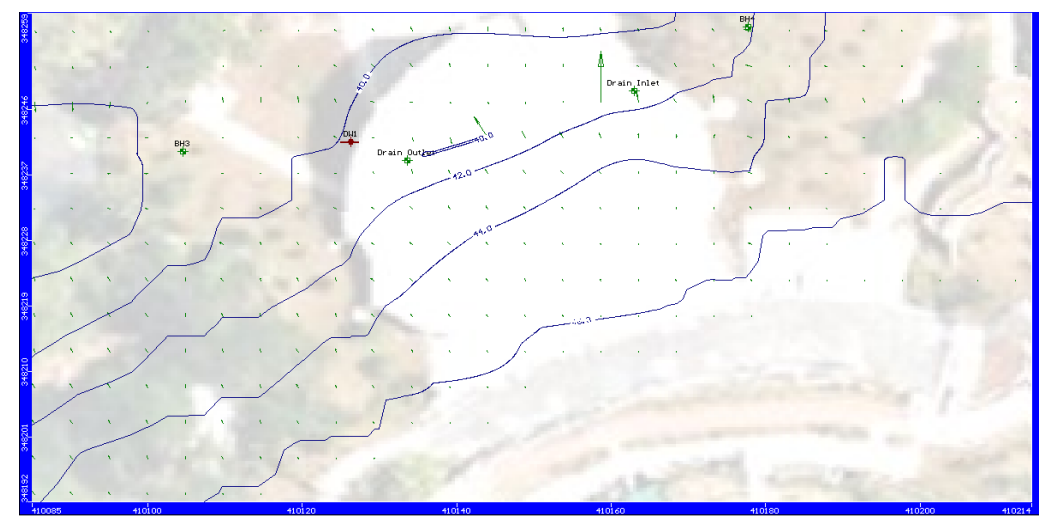

Fig. 6. Head results for Option 2

\section{Conclusion}

This study has showed that the numerical simulation groundwater flow (Visual MODFLOW), has succeeded in determining the cause of groundwater seepage problem in the study area. The elevated groundwater heads compared to the elevation levels of the area was identified as the cause for the groundwater seepage occurrence at Panggung Anniversary. The groundwater seepage caused by the increase of heads level can be overcome by reducing the head levels between $1-2 \mathrm{~m}$. In order to reduce heads level, the installation of sub-drain with dimensional design of 0.10 to $0.15 \mathrm{~m}$ (diameter), $40 \mathrm{~m}$ (length) and using $0.60 \mathrm{~m}$ depth can be used. In order to prevent any structure settlement from occurring, the safest method to be use is the dimensional design remediation with subdrain soil.

This project was supported by IKRAM Engineering Services Sdn Bhd. Many thanks also goes to all research members for their tremendous guidance and cooperation.

\section{References}

[1] M. F. Tajul Baharuddin, S. Taib, R. Hashim, M. H, Zainal Abidin, and M. F, Ishak, Time-lapse resistivity investigation of salinity changes at an ex-promontory land: a case study of Carey Island, Selangor, Malaysia, Environ. Monit. Assess., 180, 345-369, (2011)

[2] M. H, Zainal Abidin., M. F. Tajul Baharuddin, M.H. Zawawi, N. Md. Ali, A. Madun, and S.A. Ahmad Tajudin. Groundwater Seepage Mapping using Electrical Resistivity Imaging, Applied Mechanics and Materials, 1524-1534, (2015)

[3] M. F. Tajul Baharuddin, S. Taib and R. Hashim. Electrical imaging resistivity study at the coastal area of Sungai Besar, J. of Applied Sciences, 9(16), 2897-2906, (2009)

[4] M. F. Tajul Baharuddin, S. Taib, R. Hashim, M. H, Zainal Abidin, and M.A. Rashid, Evaluating freshwater lens morphology affected by seawater intrusion using chemistryresistivity integrated technique: a case study of two different land covers in Carey Island, Malaysia, Environ Earth Sci., 69, 2779-2797, (2013) 
[5] M. F. T. Baharuddin,S. A. A. Tajudin, M. H. Z. Abidin and N. A, Yusoff, Simulation of Sub-Drains Performance Using Visual MODFLOW for Slope Water Seepage Problem IOP Conf. Series: Materials Science and Engineering, 136 (2016)

[6] J. Bear and A.H.-D. Cheng, Seawater intrusion. In Modeling Groundwater Flow and Contaminant Transport, Springer Science \&Business Media, 593-636 (2010)

[7] IKRAM, Seepage Problem and Groundwater Studies at Panggung Anniversary, Taman Botani, Kuala Lumpur, IKRAM Preliminary Report, (2015)

[8] Waterloo, Visual MODFLOWv 4/1 User's Manual. Waterloo Hydrogeologic Inc., Waterloo, (2005)

[9] J. Bear, (Eds.). Hydraulics of groundwater, 384-435. New York, USA: McGraw-Hill (1979)

[10]C.W. Fetter, (Eds),Applied Hydrogeology ( $4^{\text {th }}$ Ed), New Jersey, USA: Prentice Hall Inc., 1-598,(2002)

[11]C.R. Fitts, (Eds.),Ground Water Science, London: Academic Press, (2003) 